\title{
Tingkat Pengetahuan, Sikap, dan Persepsi Mengenai Epilepsi antara Masyarakat Pedesaan dan Perkotaan di Padang
}

\author{
Hendra Permana ${ }^{1}$, Melda Yelmaiza ${ }^{2}$ \\ ${ }^{1}$ Staf Bagian Neurologi Fakultas Kedokteran Universitas Andalas / Rumah Sakit Umum Pusat dr. M. Djamil, \\ Padang, Indonesia \\ email :saint_check_lie@yahoo.com \\ ${ }^{2}$ PPDS Neurologi Fakultas Kedokteran Universitas Andalas / Rumah Sakit Umum Pusat dr. M. Djamil, Padang, \\ Indonesia
}

\begin{abstract}
Abstrak
Pendahuluan: Tingkat pengetahuan, sikap dan persepsi mengenai epilepsi pada negara berkembang termasuk Indonesia masih sangat rendah. Hal ini bisa menyebabkan terjadinya stigma dan diskriminasi pada pasien epilepsi. Tujuan: penelitian ini bertujuan untuk menggali tingkat pengetahuan, persepsi dan sikap masyarakat pedesaan dan perkotaan mengenai epilepsi. Metode: Merupakan studi cross sectional dengan desain komparatif. Penelitian ini dilakukan pada bulan Februari - Juni 2018 di puskesmas Ulak Karang (urban) dan Bungus (rural) kota Padang. Penelitian dilakukan pada 140 pengunjung puskesmas. Kriteria inklusi adalah seluruh pengunjung puskesmas yang berusia $\geq 17$ tahun dan kriteria eksklusi adalah semua data yang tidak lengkap. Data diperoleh dengan membagikan kuesioner yang terdiri dari 13 pertanyaan terstruktur. Penelitian ini sudah mendapatkan etical clearance dari komite etik Fakultas Kedokteran Universitas Andalas. Analisis menggunakan uji Manwhitney test dan Chi Square test dengan nilai p < 0,05 dianggap bermakna secara statistik. Hasil: Dari data demografi tidak terdapat perbedaan yang signifikan antara masyarakat urban dengan rural. Dalam hal pengetahuan mengenai epilepsi, terdapat perbedaan yang signifikan mengenai penyebab epilepsi dengan nilai $p=0,002$. Terdapat perbedaan signifikan persepsi mengenai stigma epilepsi yang berbeda secara signifikan pada masyarakat urban dan rural adalah mengenai malformasi pada penderita epilepsi dengan nilai $\mathrm{p}=$ 0,046 . Sedangkan untuk sikap masyarakat terhadap pasien epilepsi, tidak ada perbedaan yang signifikan antara daerah urban dengan daerah rural. Kesimpulan: Stigma menjadi hal yang menakutkan bagi penderita epilepsi, karena dapat mengganggu interaksi sosial dan mengurangi kesempatan memperoleh pekerjaan dan kesempatan menikah. Pada penelitian ini secara umum tidak didapatkan perbedaan yang signifikan mengenai pengetahuan, persepsi serta sikap masyarakat mengenai penderita epilepsi kecuali dalam hal penyebab epilepsi serta mengenai persepsi malformasi pada penderita epilepsi.
\end{abstract}

Kata Kunci: Tingkat Pengetahuan, sikap, persepsi, masyarakat, epilepsi

\begin{abstract}
Introduction: The Knowledge, perception and attitude about epilepsy in developing country, including Indonesia is still low. These problems can cause stigma and discrimination to the patient. Society still has the view that epilepsy is not a disease, but because of the inclusion of evil spirits, possessions, witches or a curse. Furthermore, the information gap between rural and urban society could contribute to the issues. Aims: This study was aimed to explore the knowledge, perception and attitude about epilepsy between rural and urban society in Padang. Method: This study used cross sectional comparative design. This study was conducted on February - June 2018 at Ulak Karang (urban) and Bungus (rural) public health center. The subjects of this study were 140 visitors of both public health centers. The inclusions criteria of this study was all visitors $\geq 17$ years old and the exclusion criteria was all incomplete data. Data was taken by using questionnaire with 13 close questions. These data was analyzed with SPSS 22. Mannwhitney tests and Chi Square test were used to compare the knowledge, perception and attitude from the two groups. A P value below 0.05 was considered asstatistically significant. Result: From demographic data, there were no significant differences between urban and rural communities. In terms of knowledge about epilepsy, there are significant differences regarding the causes of epilepsy with a value of $p=0.002$. In addition, perceptions of epilepsy stigma that
\end{abstract}

Email : heme@unbrah.ac.id 
Heme, Vol III No 1

January 2021

differed significantly in urban and rural communities were regarding malformations in epilepsy patients with $p$ $=0.046$. As for community attitudes towards epilepsy patients, there were no significant differences between urban and rural areas Conclusion: Stigma is a frightening thing for people with epilepsy, because it can interfere with their social interactions and also reduce the opportunity to get a job and also the opportunity to get married.

Key words: Knowledge, attitude, perception, society, epilepsy 


\section{Pendahuluan}

Epilepsi adalah salah satu gangguan neurologis serius yang paling umum di dunia. Diperkirakan lebih dari 70 juta orang di seluruh dunia menderita epilepsi, dan $80 \%$ hidup di negara-negara terbelakang dan berkembang secara ekonomi. Diperkirakan lebih lanjut tiga perempat orang dengan epilepsi di negara-negara berkembang tidak mendapatkan perawatan yang mereka butuhkan. ${ }^{1}$ Stigma dan masalah psikososial yang dihasilkan adalah rintangan utama yang dihadapi orang-orang dengan epilepsi dalam kehidupan sehari-hari mereka. Orang dengan epilepsi, terutama wanita, yang tinggal di negara-negara yang secara ekonomi lemah seringkali tidak memiliki kekuatan untuk menangani stigma yang mereka alami. ${ }^{2}$

Stigma mengacu pada karakteristik pribadi yang menandai seseorang yang berbeda dari biasanya dan umumnya terkait dengan penyakit dan kondisi medis yang memiliki tanda-tanda yang terlihat atau membangkitkan perasaan takut. $^{3}$ Stigma berkaitan dengan penyakit epilepsi menimbulkan banyak penderitaan diluar dari manifestasi klinis yang ditimbulkannya dan sangat mempengaruhi bagaimana orang menanggapi beban penyakit tersebut. Orang dengan epilepsi masih dipandang dengan rasa takut, kecurigaan, kesalah fahaman serta tunduk pada stigma yang mengerikan yang tampaknya dipengaruhi oleh faktor psikososial dan budaya. Selain itu, kurangnya informasi dan kepercayaan yang tidak tepat masih menjadi faktor yang paling berkontribusi terhadap stigma dan diskriminasi. ${ }^{4}$

Bagi individu dengan epilepsi di Amerika Serikat dan negara-negara lain, stigma dapat menjadi salah satu konsekuensi yang paling menyedihkan setelah kejang, bersama dengan ketidakpastian terjadinya kejang di masa depan. Dampak stigma pada kehidupan pasien epilepsi jauh lebih besar, sering termasuk efek pada hubungan interpersonal, kesehatan umum, kesempatan kerja, dan kualitas hidup secara keseluruhan. Pendidikan tentang epilepsi yang diarahkan pada komunitas yang lebih luas, serta pada individu dengan epilepsi, adalah cara yang paling efektif untuk mengatasi salah persepsi dan ketakutan. Organisasi advokasi epilepsi, seperti Epilepsy Foundation, adalah semua yang penting dalam upaya ini. ${ }^{5}$ Oleh karena itu tujuan dari penelitian ini adalah untuk mengetahui tingkat pengetahuan, sikap dan persepsi antara pada masyakarat rural dan urban di kota Padang Sumatera Barat.

\section{Metode Penelitian}

Penelitian dilakukan di Padang Sumatra barat pada bulan Februari 2018. Penelitian ini telah disetujui oleh Komite Etika Fakultas Kedokteran Universitas Andalas. Studi cross sectional ini melibatkan 70 orang dari pengunjung puskesmas yang berada di daerah pedesaan dan 70 orang pengunjung puskesmas yang berada di daerah perkotaan. Penelitian ini dilakukan dengan menyebarkan kuesioner kepada para pengunjung puskesmas di kedua tempat tersebut. Setelah izin diperoleh dari kepala puskesmas, kuesioner diberikan kepada seluruh populasi penelitian. Kuesioner diberikan dalam Bahasa Indonesia. Kekurangan dari penelitian ini adalah kuesioner dalam penelitian ini tidak diuji terlebih dahulu sehingga belum diketahui secara pasti apakah kuesioner tersebut mudah dimengerti atau tidak. Mereka yang berusia 17 tahun dan lebih tua dimasukkan sebagai peserta setelah diberikan informed consent dan diminta untuk mengisi kuesioner. Data yang tidak lengkap dikeluarkan dalam analisis.

Kuesioner terdiri dari 13 item, diterjemahkan ke bahasa Indonesia digunakan untuk wawancara. Kuesioner ini diadaptasi dari kuesioner lain untuk survei epilepsi yang telah dilakukan di tempat lain. Kuesioner dibagi menjadi dua bagian; bagian pertama berisi data sosio-demografi responden 
termasuk usia, jenis kelamin dan pendidikan. Bagian kedua berisi pertanyaan yang digunakan untuk mengevaluasi pengetahuan dan persepsi tentang epilepsi. Pertanyaanpertanyaan ini termasuk; pengetahuan tentang apakah penyebab epilepsi, apakah epilepsi adalah keterbatasan, asal epilepsi, tindakan yang diambil ketika melihat pasien kejang, pengobatan epilepsi. Untuk persepsi mereka, kuesioner mengevaluasi apakah responden mengetahui tentang pasien epilepsi: diizinkan untuk mengemudi, memiliki kesempatan kerja yang lebih sedikit, dapat melakukan segala jenis kegiatan profesional, akan menerima perawatan yang lebih baik di rumah sakit, memiliki kapasitas kognitif yang buruk (belajar dan memori), memiliki risiko lebih besar mengembangkan gangguan mental, memiliki jangkauan terbatas aktivitas fisik, dapat menikah, harus terdaftar di sekolah khusus, dapat berpartisipasi dalam kegiatan olahraga tetapi dengan pembatasan, dapat memiliki anak. Untuk menilai sikap responden terhadap penderita epilepsi diajukan pertanyaan berupa apa yang mereka rasakan saat melihat orang kejang. Sebagian besar pertanyaannya adalah pertanyaan terbuka sederhana yang membutuhkan jawaban 'ya' atau 'tidak'. Selanjutnya semua data dianalisis menggunakan uji Manwhitney test dan Chi Square test dengan nilai $\mathrm{p}<$ 0,05 dianggap bermakna secara statistik.

\section{HASIL}

Pada penelitian ini didapatkan sebaran karakteristik berdasarkan usia responden dimulai dari usia 17 tahun hingga 73 tahun, dengan usia rata-rata 30 tahun. Data demografi pasien terdiri dari usia, jenis kelamin dan tingkat pendidikan. Dari data demografi tersebut tidak ada perbedaan yang signifikan antara daerah rural dengan daerah urban. Hal ini dapat dilihat pada tabel 1 .
TABEL 1. DATA DEMOGRAFI RESPONDEN

\begin{tabular}{llccc}
\hline & & \multicolumn{2}{c}{ Grup } & p \\
\cline { 3 - 4 } & & $\begin{array}{c}\text { Urban } \\
\text { (f) }\end{array}$ & $\begin{array}{c}\text { Rural } \\
\text { (f) }\end{array}$ & \\
\hline Jenis & Laki-laki & 23 & 30 & 0.223 \\
Kelamin & Perempuan & 47 & 40 & \\
Median & (min-max) & 34.5 & 30 & 0.403 \\
Umur & & $(17-73)$ & $(17-58)$ & \\
Pendidikan & SD-SMP & 15 & 14 & 0.535 \\
& SMA-Kuliah & 55 & 56 & \\
\hline
\end{tabular}

Berdasarkan tabel 2, tidak ada perbedaan yang signifikan mengenai informasi epilepsi yang diperoleh kedua golongan masyarakat baik rural maupun urban, kecuali mengenai penyebab epilepsi. Terdapat perbedaan yang signifikan antara masyarakat rural dan urban mengenai penyebab epilepsi, dengan nilai $\mathrm{p}=0,002$. Dari 70 responden masyarakat rural, 53 responden berpendapat bahwa epilepsi bukan disebabkan oleh trauma, tetapi oleh penyebab lain seperti karena infeksi.

\section{TABEL 2. INFORMASI MENGENAI EPILEPSI}

\begin{tabular}{|c|c|c|c|}
\hline \multirow[b]{2}{*}{ Jawaban } & \multicolumn{2}{|c|}{ Grup } & \multirow[b]{2}{*}{$\mathbf{P}$} \\
\hline & $\begin{array}{c}\text { Urban } \\
\mathbf{f}=70\end{array}$ & $\begin{array}{c}\text { Rural } \\
\mathbf{f}=70\end{array}$ & \\
\hline $\begin{array}{l}\text { Informasi yang } \\
\text { diterima mengenai } \\
\text { epilepsi }\end{array}$ & & & 0.310 \\
\hline Kurang & 30 & 36 & \\
\hline Cukup & 40 & 34 & \\
\hline Asal epilepsi & & & 0.07 \\
\hline Neurologi & 42 & 26 & \\
\hline Non-neurologi & 28 & 44 & \\
\hline Penyebab epilepsi & & & 0.002 \\
\hline Trauma & 35 & 17 & \\
\hline $\begin{array}{l}\text { Penyebab } \\
\text { lainnya }\end{array}$ & 35 & 53 & \\
\hline Terapi & & & 0.236 \\
\hline Obat-obatan & 41 & 34 & \\
\hline Terapi lain & 29 & 36 & \\
\hline $\begin{array}{l}\text { Informasi ttg } \\
\text { epilepsi diperoleh } \\
\text { dari }\end{array}$ & & & 0.370 \\
\hline Dokter & 10 & 14 & \\
\hline Lainnya & 60 & 56 & \\
\hline
\end{tabular}


Tabel 3 menggambarkan mengenai persepsi masyarakat pedesaan dan perkotaan mengenai persepsi epilepsi. Ada beberapa persepsi masyarakat mengenai stigma pada pasien epilepsi, stigma tersebut diantaranya mengenai menikahi pasien epilepsi, mempekerjakan mereka, pasien epilepsi memiliki tingkat kecerdasan yang buruk, berisiko tinggi memiliki kelainan mental, pasien epilepsi seharusnya dirawat dirumah sakit, mereka tidak diizinkan untuk mengemudi, mereka memiliki kelainan kongenital yang lain. Tidak ada perbedaan yang signifikan mengenai persepsi masyarakat rural dan urban mengenai stigma ini, kecuali mengenai kelainan kongenital pada pasien epilepsi, terdapat perbedaan yang signifikan mengenai hal ini dengan nilai $\mathrm{p}=0.046$.

TABel 3. Persepsi mengenai Stigma EPILEPSI

\begin{tabular}{|c|c|c|c|}
\hline \multirow[b]{2}{*}{ Jawaban } & \multicolumn{2}{|c|}{ Grup } & \multirow[b]{2}{*}{$\mathbf{P}$} \\
\hline & $\begin{array}{c}\text { Urban } \\
\text { (f) }\end{array}$ & $\begin{array}{c}\text { Rural } \\
\text { (f) }\end{array}$ & \\
\hline $\begin{array}{l}\text { Menikah dengan pasien } \\
\text { epilepsi }\end{array}$ & & & 0.532 \\
\hline $\mathrm{Ya}$ & 13 & 16 & \\
\hline Tidak dan tidak tahu & 57 & 54 & \\
\hline $\begin{array}{l}\text { Mempekerjakan pasien } \\
\text { epilepsi }\end{array}$ & & & 0.384 \\
\hline $\mathrm{Ya}$ & 24 & 29 & \\
\hline Tidak dan tidak tahu & 46 & 41 & \\
\hline $\begin{array}{l}\text { Memiliki kecerdasan yang } \\
\text { buruk }\end{array}$ & & & 0.559 \\
\hline $\mathrm{Ya}$ & 29 & 35 & \\
\hline Tidak dan tidak tahu & 41 & 35 & \\
\hline $\begin{array}{l}\text { Berisiko memiliki } \\
\text { penyakit mental }\end{array}$ & & & 0.215 \\
\hline $\mathrm{Ya}$ & 42 & 49 & \\
\hline Tidak dan tidak tahu & 28 & 21 & \\
\hline Seharusnya dirawat di RS & & & 0.467 \\
\hline $\mathrm{Ya}$ & 45 & 41 & \\
\hline Tidak dan tidak tahu & 25 & 29 & \\
\hline Diizinkan mengemudi & & & 0.370 \\
\hline $\mathrm{Ya}$ & 14 & 10 & \\
\hline Tidak dan tidak tahu & 56 & 60 & \\
\hline Memiliki malformasi & & & 0.046 \\
\hline
\end{tabular}

Dalam hal sikap masyarakat terhadap pasien epilepsi antar masyarakat rural dan urban tidak ada perbedan yang signifikan. Berbagai sikap ditunjukkan oleh masyarakat ketika menghadapi pasien epilepsi saat serangan diantaranya menahan lidahnya, memberikan sesuatu yang berbau kuat, memercikkan air kewajahnya, menahan gerakannya. Pada kedua kelompok masyarakat ini, mereka lebih sering melakukan tindakan-tindakan tersebut saat melihat pasien kejang ketimbang melindungi kepala pasien. Berbagai sikap yang diambil oleh masyarakat ini sangat dipengaruhi oleh pendidikan yang diterima oleh masyarakat terutama pendidikan mengenai epilepsi. Hal ini dijelaskan dalam tabel 4 .

\section{TABEL 4. SIKAP TERHADAP PASIEN EPILEPSI}

\begin{tabular}{lccc}
\hline \multirow{1}{*}{ Jawaban } & \multicolumn{2}{c}{ Grup } & \multirow{2}{*}{ p } \\
\cline { 2 - 3 } & Urban (f) & Rural (f) & \\
\hline Tindakan saat melihat & & & 0.270 \\
pasien kejang & & & \\
$\quad$ Melindungi kepala & 15 & 10 & \\
$\quad$ Lainnya & 55 & 60 & \\
Perasaan & & & 0.610 \\
$\quad$ Ingin membantu & 33 & 30 & \\
$\quad$ Lainnya & 37 & 40 & \\
\hline
\end{tabular}

\section{Pembahasan}

Stigma yang diterima oleh penderita epilepsi adalah suatu hal yang merugikan pasien dalam berbagai aspek kehidupan. Stigma juga memiliki dampak sosial dan dapat menyebabkan kesulitan dalam membangun interaksi sosial dan kesulitan dalam menjalani kehidupan normal. ${ }^{4}$ Diantaranya dalam hal pernikahan, banyak orang yang tidak mau menikah dengan pasien epilepsi, pada penelitian ini antara masyarakat rural dan urban tidak ada perbedaan yang signifikan, dengan nilai $\mathrm{p}=0.532,57$ responden dari 70 masyarakat urban, 54 responden dari 70 masyarakat rural tidak ingin menikah ataupun menikahkan anggota keluarganya dengan pasien epilepsi. Penelitian Fekadu mengenai persepsi dan sikap masyarakat terhadap pasien epilepsi di Etiopia mengatakan bahwa hanya $6.7 \%$ responden yang setuju menikahkan anggota keluarganya dengan pasien epilepsi. ${ }^{6}$ Pada 
penelitian Kaddumukasa dikatakan 60,5\% responden menyatakan bahwasanya mereka menolak anak mereka bermain atau bahkan menikah dengan pasien epilepsi. ${ }^{7}$ Demikian pula dalam hal pekerjaan, penderita epilepsi memiliki peluang yang terbatas dalam hal lapangan pekerjaan. Banyak masyarakat yang tidak mau mempekerjakan karyawan yang menderita epilepsi. ${ }^{4}$ Pada penelitian ini terlihat tidak ada perbedaan yang signifikan dalam hal mempekerjakan pasien epilepsi sebagai karyawan. Masyarakat urban maupun daerah rural masih enggan untuk mempekerjakan karyawan dari penderita epilepsi. Hal yang sama terlihat pada hasil penelitian oleh Fekadu 2019, dari 660 partisipan dari 701 partisipan $(94,2 \%)$ tidak akan mempekerjakan karyawan yang menderita epilepsi. ${ }^{7}$ Bahkan menurut penelitian Millogo 2019, di Zambia penderita epilepsi tidak dapat menikah dan tidak dapat dipekerjakan. ${ }^{8}$

Dalam penelitian ini terdapat perbedaan yang signifikan mengenai penyebab epilepsi menurut masyarakat rural dan urban dengan nilai $p=0,002$. bahwasanya epilepsi disebabkan oleh penyebab lain selain oleh trauma, seperti karena penyebab infeksi dan penyebab lainnya.

Terdapat perbedaan yang signifikan mengenai persepsi masyarakat rural dan urban tentang stigma pada pasien epilepsi yaitu bahwasanya penderita epilepsi memiliki malformasi yang lain dengan nilai $\mathrm{p}=0,046$. Sebanyak 26 dari 70 masyarakat rural menjawab "ya" dan sebanyak 55 orang dari 70 masyarakat urban menjawab tidak.

\section{KESIMPULAN DAN SARAN}

Stigma adalah sesuatu masalah yang sangat menakutkan bagi penderita epilepsi. Stigma ini sangat memberikan dampak sosial, yaitu mengganggu interaksi sosial pada penderita sehingga menyebabkan mereka tidak dapat menjalani kehidupan normal dengan layak. Banyak hal yang terdampak dari adanya stigma ini diantaranya adalah kesempatan untuk mendapatkan pekerjaan, kesempatan menikah sebagaimana mestinya. Dalam penelitian ini tidak didapatkan perbedaan yang signifikan dalam hal pengetahuan sikap dan persepsi antara masyarakat urban dan masayarakat rural dikota Padang kecuali dalam hal pandangan mengenai penyebab epilepsi dan adanya kelainan kongenital lain pada pasien epilepsi. Oleh karenanya edukasi kesehatan mengenai epilepsi ini merupakan suatu keniscayaan yang harus segera diwujudkan baik terhadap masyarakat urban maupun rural, sehingga diharapkan penderita epilepsi ini bisa hidup secara normal ditengah-tengah masyarakat.

\section{Daftar Pustaka}

[1] Kaddumukasa M, Kakooza A, Kayima J, Kaddumukasa N M,Ddumba E, Mugenyi L, et al. Community knowledge of and attitudes toward epilepsy in rural and urban Mukono district, Uganda: A cross-sectional study. Epilepsy and Behavior. 2016; 54: 7-11

[2] Thomas Sanjeev, Nair Aparna. Confronting the stigma of epilepsy. Journal of Indian Academy of Neurology. 2011. Vol 14(3); 158-163.

[3] Diiorio C. The association of stigma with selfmanagement and perceptions of health care among adults with epilepsy. Elsevier, Epilepsy \& Behavior. 2003. Vol 4: 259-267.

[4] Luna J, Nizard M, Becker D, Gerard D, Cruz A, Ratsimbazafy V, et al. Epilepsy-associated levels of perceived stigma, their associations with treatment, and related factors: A cross-sectional study in urban and rural areas in Ecuador. Epilepsy \& Behaviour. 2017. Epilepsy \& Behaviour. Vol 68, 71-77.

[5] Morrell J Martha. ' Epilepsy and Behavior', Elsevier. 2002.Volume 3, 21-25

[6] Fekadu W, Mekonen T, Bitew S, Mekonen C T, Menberu M, Shewangizaw S. Community's perception and attitude towards people with epilepsy in ethiopia. Hindawi Behavioural Neurology. 2019.

[7] Kaddumukasa M, Kaddumukasa N M, Buwembo W, Munabi I, Blixen C, Lhatoo S, et al. Epilepsy misconceptions and stigma reduction interventions in sub-Saharan Africa, a systematic review. Epilepsy and Behavior. 2018. Vol 85; 21-27.

[8] Millogo A, Ngowi H A, Carabin H, Ganaba R, Da A, Preux P. Knowledge, attitudes, and practices related to epilepsy in rural burkina faso. Epilepsy \& Behavior. 2019. Vol 95; 70-74. 